\title{
CAEP 2014 Academic symposium: "How to make research succeed in your department: How to fund your research program"
}

Christian Vaillancourt, MD, MSc**; Brian H. Rowe, MD, MSc ${ }^{\ddagger \S}$; Jennifer D. Artz, PhD"; Robert Green, BSc, MD** ${ }^{* \dagger}$; Marcel Émond, MD, MSc ${ }^{\ddagger \ddagger \S \S ; ~ V e n k a t e s h ~ T h i r u g a n a s a m b a n d a m o o r t h y, ~}$ MBBS, $\mathrm{MSc}^{*^{+}}$; Grant Innes, MD ${ }^{\text {IT; }}$; Jeffrey J. Perry, MD, MSc ${ }^{* \dagger}$; Lisa A. Calder, MD, MSc ${ }^{{ }^{+}}$; Ian G. Stiell, MD, $\mathrm{MSc}^{*}$

\section{ABSTRACT}

Objective: We sought to gather a comprehensive list of funding strategies and opportunities for emergency medicine (EM) centres across Canada, and make recommendations on how to successfully fund all levels of research activity, including research projects, staff salaries, infrastructure, and researcher stipends.

Methods: We formed an expert panel consisting of volunteers recognized nationally for their scholarly work in EM. First, we conducted interviews with academic leaders and researchers to obtain a description of their local funding strategies using a standardized open-ended questionnaire. Panelists then identified emerging funding models. Second, we listed funding opportunities and initiatives at the provincial, national, and international levels. Finally, we used an iterative consensusbased approach to derive pragmatic recommendations after incorporating comments and suggestions from participants at an academic symposium.

Results: Our review of funding strategies identified four funding models: 1) investigator dependent model, 2) practice plan, 3) generous benefactor, and 4) mixed funding. Recommendations in this document include approaches for research contributors and producers (seven recommendations), for local academic leaders (five recommendations), and for national organizations, such as the Canadian Association of Emergency Physicians (CAEP) (three recommendations).

Conclusions: Funding for research in EM varies across Canada and is largely insecure. We offer recommendations to help facilitate funding for large and small projects, for salary support, and for local and national leaders to advance EM research. We believe that these recommendations will increase funding for all levels of EM research activity, including research projects, staff salaries, infrastructure, and researcher stipends.

\section{RÉSUMÉ}

Objectifs: Le groupe visait à dresser une liste exhaustive de stratégies et de possibilités de financement pour les centres de recherche en médecine d'urgence (MU) partout au Canada, et à faire des recommandations sur la manière d'assurer le financement de l'ensemble de l'activité de recherche, soit les projets de recherche comme tels, le salaire du personnel, l'infrastructure et les allocations aux chercheurs.

Méthode: Un groupe d'experts composé de bénévoles bien connus à l'échelle nationale pour leurs travaux savants en MU a été formé. Celui-ci a d'abord eu des entretiens avec des chefs de file en milieu universitaire et des chercheurs pour connaître leurs stratégies de financement local, et ce, à l'aide d'un questionnaire à réponses libres. Les membres du groupe ont dégagé de nouveaux modèles de financement. A ensuite été dressée une liste de possibilités et d'initiatives de financement aux niveaux provincial, national et international. Enfin, le groupe a formulé des recommandations pragmatiques selon un processus consensuel itératif après avoir tenu compte des observations et des suggestions faites par les participants à un symposium sur les affaires universitaires.

Résultats: L'examen des stratégies de financement a permis de relever quatre modèles de financement: 1) le modèle tributaire du chercheur, 2) le modèle du plan de pratique; 3) le modèle du généreux bienfaiteur, et 4) le modèle de financement mixte. Le présent document contient des recommandations qui s'adressent tant aux contributeurs à la recherche et aux producteurs (sept recommandations) qu'aux chefs de files locaux en milieu universitaire (cinq recommandations) et aux organisations nationales telles que I'ACMU (trois recommandations).

Conclusions: Le financement de la recherche en MU varie d'une région à l'autre au Canada et il est très précaire.

From the *Department of Emergency Medicine, University of Ottawa, Ottawa, ON; +Ottawa Hospital Research Institute, Clinical Epidemiology Program, Ottawa, ON; ¥Department of Emergency Medicine, University of Alberta, Edmonton, AB; §School of Public Health, University of Alberta, Edmonton, $A B$; $\lceil$ Canadian Association of Emergency Physicians, Ottawa, ON; **Department of Emergency Medicine, Dalhousie University, Halifax, SC; ††Department of Critical Care Medicine, Dalhousie University, Halifax, NS; ł‡Department of Emergency and Family Medicine, Laval University, Quebec, QC; §§Trauma-Emergency and ICU Research Unit, Centre hospitalier universitaire de Québec, Quebec, QC; and ITIDepartment of Emergency Medicine, University of Calgary, Calgary, AB.

Correspondence to: Dr. Christian Vaillancourt, Ottawa Hospital, Civic Campus, Clinical Epidemiology Unit, F649, 1053 Carling Ave., Ottawa, ON K1Y 4E9; Email: cvaillancourt@ohri.ca

(C) Canadian Association of Emergency Physicians 
Des recommandations ont été élaborées afin de faciliter le financement de petits et de gros projets de recherche ainsi que l'obtention d'aide salariale, en plus de soutenir les chefs de file locaux et nationaux dans leur tâche de faire progresser la recherche en $\mathrm{MU}$. Le groupe est d'avis que ces recommandations auront pour effet d'accroître le financement de l'ensemble de l'activité de recherche en
$\mathrm{MU}$, soit les projets de recherche comme tels, le salaire du personnel, l'infrastructure et les allocations aux chercheurs.

Keywords: emergency medicine, faculty, learners, mid-career investigators, research funding, senior investigators, young investigators

\section{INTRODUCTION}

\section{Background}

Emergency medicine (EM) is a relatively young specialty with dedicated training programs initially established in the early seventies. Since then, the scope of EM practice has expanded, residency programs and research demands have increased, and academic productivity has grown. Scholarly work is essential to the development of best clinical practices, of academic careers, and of mutual respect and collaboration with other specialties. ${ }^{1-4}$ Most importantly, research can lead to high-quality care and improved outcomes for patients, and to improved efficacy and cost savings for health organizations. ${ }^{5-13}$ Research funding has a critical impact on the ability of researchers to complete projects, the training and retention of young investigators, and improving emergency health care delivery in Canada.

\section{Importance}

There is limited existing literature on research funding strategies for EM investigators and programs, especially in Canada. ${ }^{14} \mathrm{~A}$ comprehensive guiding document describing funding strategies and opportunities could be helpful to researchers and academic leaders, and increase EM research capacity at an individual, institutional, and national levels. Although there are growing numbers of trained EM investigators, ${ }^{15}$ most academic centres still find themselves without the critical mass of researchers necessary to support a successful research program and mentor young investigators. Canadian academic centres have developed diverse strategies to fund scholarly activity-some with more success than others. There is a general consensus within the EM research community that the current approaches to research funding are poorly understood, inefficient, and not focused on sustainability. Our current academic environment makes it difficult for programs and individual researchers to reach their full potential. EM researchers and leaders can benefit from the experience of those who have developed funding strategies to support the academic mission at their institution.

\section{Objectives}

We sought to gather a comprehensive list of funding strategies and opportunities for EM centres across Canada, and make recommendations on how to successfully fund all levels of research activity, including research projects, staff salaries, infrastructure, and researcher stipends.

\section{METHODS}

\section{Design}

In 2014, the academic section of the Canadian Association of Emergency Physicians (CAEP) held a symposium titled: "How to Make Research Succeed in your Department." This academic symposium focused its attention on three main areas, one of which was on how to fund a research program. An overview of all three areas discussed can be found in the Executive Summary. ${ }^{16}$ Fellows of the Royal College of Physicians of Canada (FRCPC) and EM-trained members of the College of Family Physicians of Canada (CFPC) were equally represented on the panel.

Each panel was asked to define the target audience for its recommendations. By consensus, panelists identified the following stakeholders: 1) research contributors and producers, including medical students, residents, fellows, faculty members without research training, young investigators, and mid-career and senior investigators ${ }^{17}$; 2) local academic leaders; and 3) national organizations.

\section{Description of local or institutional funding models}

Panelists were responsible for identifying current or past research funding models from across Canada, 
starting within their respective geographical areas. They contacted academic leaders and researchers from those institutions to obtain a description of their local funding strategies. This initial purposeful sampling was followed by a snowball sampling strategy, where individuals first contacted were asked to identify colleagues with innovative and successful strategies. All interviews were conducted in person or by telephone using a standardized open-ended questionnaire developed by the panelists (Appendix 1). Information was collated, summarized, checked for accuracy, and shared with the panelists, who then identified emerging themes. We conducted interviews until no new funding models could be identified.

\section{Funding opportunities at the provincial, national, and international levels}

Panelists worked collaboratively to identify provincial, national, and international funding sources. Because it was beyond the scope and resources of the panel to develop an exhaustive list, the process was designed to inform our target audience about common EM research funding sources. We did not attempt to list all diseasespecific sources (e.g., Multiple Sclerosis Society of Canada).

We did not attempt to identify all possible international funding sources, but we did compile many U.S. opportunities, some of which are available to Canadians, by gathering information from the Society for Academic Emergency Medicine (SAEM), the American College of Emergency Physicians (ACEP), and the National Institutes of Health (NIH).

\section{Recommendation development}

We used an iterative consensus-based approach to draft pragmatic recommendations targeting research contributors and producers, local academic leaders, and national organizations. We presented these draft recommendations for discussion at the 2014 CAEP Academic Symposium, which was attended by 80 individuals. Attendees included EM researchers, educators, administrators, clinicians, and residents. We subsequently revised our final recommendations after incorporating the feedback received during the academic symposium.

\section{RESULTS}

\section{Description of local or institutional funding models}

Our panelists interviewed twenty-one academic leaders and researchers from nine provinces. We could not obtain information from Prince Edward Island, Yukon, the Northwest Territories, or Nunavut. The list of people who contributed information to this panel is presented in Figure 1. They provided us with a wide variety of strategies that we classified in one of the following four funding models (Figure 2).

\section{Investigator-dependent model}

In this model, research activity is often limited to one or a few investigators. Funding is largely obtained through

\begin{tabular}{|ccc|}
\hline British Columbia & Ontario & New Brunswick \\
Rob Stenstrom & Guy Hébert & Paul Atkinson \\
Riyad Abu-Laban & Laurie Morrison & \\
& Jonathan Dreyer & Nova Scotia \\
Alberta & Shelley McLeod & Kirk Magee \\
Eddy Lang & Andrew Worster & Robert Green \\
Brian Rowe & Howard Ovens & \\
& & Newfoundland \\
Saskatchewan & Québec & Kris Aubrey-Bassler \\
Rob Woods & Marc Afilalo & \\
& Raoul Daoust & National Institutes of Health \\
Manitoba & Janusz Kaczorowski & Jeremy Brown \\
Alecs Chochinov & Guy Béland & \\
& Jean-Marc Troquet & \\
\hline
\end{tabular}

Figure 1. List of people contributing information to this panel.*

${ }^{*} B R$ and $R G$ contributed directly to the content, and CV, BR, $\mathrm{RG}, \mathrm{ME}, \mathrm{VT}$, and GI conducted the interviews.

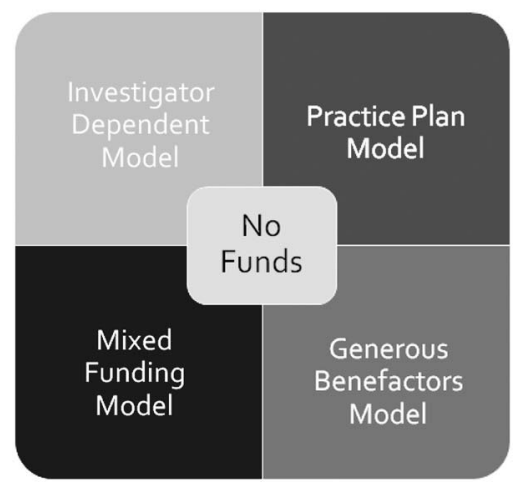

Figure 2. Funding models identified by the panel by way of consensus after completion of interviews with regional academic leaders and researchers. 
targeted and opportunistic applications and is available on a project-by-project basis. Funding sources can include, but are not limited to, a combination of industry, small internal awards, or peer-reviewed external awards. Research activity at institutions employing this approach relies almost entirely on the continuous presence of these dedicated investigators. The research program dissolves when funding or resources are expended or the investigator departs.

\section{Practice-plan model}

In this model, core funding is provided via "tithing" from clinical earnings or as part of an academic payment plan. This model is also employed by many other specialties across Canada (including surgery, medicine, and psychiatry). However, this approach provides limited resources in absence of other sources of funding. Resulting support is often limited to resident research or minimal support for faculty. In some locations, this model has been used to support investigators' salary and provide support staff.

\section{Generous-benefactor model}

Few clinical research groups have attracted large sums of money from private donors, but illustrative examples include the Schwartz/Reisman Emergency Medicine Research Institute at Mount Sinai, Toronto, the Li Ka Shing Knowledge Institute at St. Michael's, Toronto, and the $\mathrm{Li} \mathrm{Ka}$ Shing Institute of Virology at University of Alberta. For the most part, these models provide infrastructure support rather than project funding or investigators' salary. Other examples include salary support for investigators from industry partners such as the mining industry (St. Paul's Hospital in Vancouver), the pharmaceutical industry (no examples in Canadian $\mathrm{EM}$ ), or the railway industry (Pediatric Emergency Medicine, University of Calgary). Similar funding was obtained to secure an endowed chair in EM through Alberta Health Services (University of Alberta).

\section{Mixed-funding model}

This model involves practice-plan supported investigators seeking additional funds through peer-reviewed grant applications or other diverse sources, including 1) universities, 2) research institutes, 3) hospital foundations, 4) regional associations, 5) provincial or health ministry funds, and 6) clinical research networks.

University support is more often available for education activities rather than research. Where research support is offered, it can take to form administrative staff, salary support for investigators, research chairs, summer student funding, or in-kind support to access a methodology centre. One example of university support is Manitoba's Research Education and Innovation (REdI) Fund. Budgetary surplus following the foundation of their emergency department was allowed to carry over in support of various research programs and activities. The foundation of a new department or the recruitment of a new chair is an excellent opportunity to negotiate university funding.

Some institutions are affiliated with research institutes. They can provide investigator salary support or access to a methodology centre. Some of them also offer small internal operating grants. The Ottawa Hospital Research Institute, les Centres de Recherche en Santé du Québec, and Dalhousie's Research Method Unit are examples offering such services.

Hospital foundations can help with targeted fundraising. They often offer small operating grants, but those are rarely focused on EM. They can offer endowment funds for research chairs, often with matching funds from the receiving academic group (e.g., The Ottawa Hospital Foundation Chair in Emergency Medicine Research).

We have also identified a number of regional associations that can offer small grants for research or quality assurance projects. Those include the Regional Medical Association of Hamilton, the Association of Department Heads in Toronto, the Edmonton Emergency Physicians Association (EEPA), and various emergency medical services and regional associations.

A number of provinces also offer research funding to institutions. The British Columbia Ministry of Health provides funds in support of its strategic interests. Those funds are negotiated annually and are used as matching funds to help obtain funding from other sources. Alberta Health Services provides salary support for some investigators at University of Calgary, and provides other support for investigators province-wide. Alberta Health Services also provides a research platform that helps support investigators' activities (Emergency Strategic Clinical Network). Le Fond de Recherche en Santé du Québec (FRSQ) provides financial support both for infrastructure and support staff, and for operating grants. Ontario, New Brunswick, and Nova Scotia provide academic funds through alternate funding plans (AFP). These are meant to compensate clinicians for their academic work, but the 
way these funds are used varies among institutions. Some groups simply distribute the funds to their physicians, whereas others fund academic activities through point reward systems and internal small grants $(\$ 5,000$ to $\$ 10,000)$, or fund new academic positions, research methodologists, and support staff.

Finally, successful institutions often belong to clinical research networks and can secure funding that leads to opportunities for EM. Examples of such networks include the CAEP Research Consortium, the Pediatric Emergency Research Consortium (PERC), the Resuscitation Outcomes Consortium (ROC), the Canadian Institutes of Health Research's (CIHR) Strategy for Patient Oriented Research (SPOR) network, the Networks of Centers of Excellence (e.g., AllerGen for asthma and allergy projects), the Agency for Healthcare Research and Quality (AHRQ), the Canadian Agency for Drugs and Technologies in Health (CADTH), and networks sponsored by the FRSQ.

Based on our review of various funding models, the mixed-funding model appears to represent the most viable model to sustain research activities over time. There is a variety of ways to reach this goal; however, academic centres wanting to support research activities should explore the possibility of adopting a practice plan. This would also facilitate recruiting or retaining researchers with established funding (investigator-dependant model). Generous benefactors usually support activities in large urban centres and will usually not support EM research unless a critical mass of proven researchers coexist and collaborate.

\section{Funding opportunities at the provincial or national level}

Table 1 is a list of commonly used sources for EM peer-reviewed funding. Of note, the FRSQ offers an EM-specific funding program. Each source has eligibility criteria and budgetary constraints with which applicants must familiarize themselves. Some of the strategic funding initiatives change over time, and specific requests for applications are announced on a regular basis. Researchers should join distribution lists in order to take advantage of such opportunities.

\section{International funding opportunities}

Canada's proximity to the United States (USA) lends itself to cross-border collaborations. This enables mid-career and senior investigators (rarely junior investigators) to participate in grant applications submitted to the USA NIH. In 2012, the Office of Emergency Care Research (OECR) was created in response to three reports by the Institute of Medicine highlighting the challenges of emergency medical care in the USA. ${ }^{18-20}$ The OECR is housed in the National Institute of General Medical Sciences (NIGMS), one of the NIH's 27 institutes. The OECR coordinates and fosters the conduct of research and aims to improve research training in emergency department settings. Funding sources other than the NIH are also listed in Table 1.

ACEP's Emergency Medicine Foundation provides US\$250,000 to US\$300,000 in grant support annually. SAEM holds annual grant competition offering funding for education fellowships, as well as institutional, and individual research training grants. Each of the three grants is valued at US\$100,000 over 2 years. This includes a toxicology scholarship (US\$1,500) and various travel awards. Smaller grants are available to Canadians for research involving EM interest groups (US\$500) and for medical student research (US\$2,400). Canadian researchers should carefully check their eligibility prior to application, because some grants are restricted to U.S. citizens or to those with at least 1-year membership (e.g., SAEM).

After having explored local, provincial, national, and international levels of funding, panelists attempted to highlight which of those were most relevant to our target audience. This is illustrated in Figure 3.

\section{ACADEMIC SYMPOSIUM}

We received many comments and suggestions from people attending the academic symposium. Many stressed the importance for local academic leadership to have a long-term vision and advocate for increased research support. They also highlighted the importance of mentors in helping young investigators obtain research funding. A suggestion was made that, early on, young investigators should concentrate on publishing manuscripts in order to become more competitive. In addition, careful consideration should be given to the appropriate timing of their first academic appointment. Young investigators are often only eligible for new investigator salary awards during the first 5 to 7 years following their first academic appointment. EM's relationship with industry was also raised. It was felt that this source of funding is underutilized for fear of being in or having to report a conflict of interest. In addition, the role of CAEP and the possibility of an expanded 


\begin{tabular}{|c|c|c|}
\hline Level of funding & Funding agency & Full name \\
\hline \multirow[t]{5}{*}{ International } & ACEP & American College of Emergency Physicians \\
\hline & $\mathrm{AHA}$ & American Heart Association \\
\hline & AHRO & Agency for Healthcare Research and Quality \\
\hline & $\mathrm{NIH}$ & National Institutes of Health \\
\hline & SAEM & Society for Academic Emergency Medicine \\
\hline \multirow[t]{12}{*}{ National } & AllerGen NCEs & AllerGen Networks of Centers of Excellence \\
\hline & CADTH & Canadian Agency for Drugs and Technologies in Health \\
\hline & CAEP & Canadian Association of Emergency Physicians \\
\hline & $\mathrm{CFHI}$ & Canadian Foundation for Healthcare Improvement \\
\hline & $\mathrm{CFI}$ & Canadian Foundation for Innovation \\
\hline & CHSRF & Canadian Health Services Research Foundation \\
\hline & ClHR & Canadian Institutes of Health Research \\
\hline & CPSI & Canadian Patient Safety Institute \\
\hline & CSJ & Canada Summer Job \\
\hline & DRDC & Defence Research and Development \\
\hline & HSFC & Heart and Stroke Foundation of Canada \\
\hline & RCPSC & Royal College of Physicians and Surgeons of Canada \\
\hline \multicolumn{3}{|l|}{ Provincial } \\
\hline British Columbia & MSF & Michael Smith Foundation \\
\hline \multirow[t]{4}{*}{ Alberta } & AHS & Alberta Health Services \\
\hline & AlHS & Alberta Innovated Health Solutions \\
\hline & $\mathrm{HQCA}$ & Health Quality Council of Alberta \\
\hline & MSI & Medical Services Incorporated Foundation \\
\hline \multirow[t]{2}{*}{ Saskatchewan } & ISF & Innovation and Science Fund \\
\hline & SHRF & Saskatchewan Health Research Foundation \\
\hline \multirow[t]{4}{*}{ Manitoba } & $\mathrm{MICH}$ & Manitoba Institute of Child Health \\
\hline & MMSF & Manitoba Medical Service Foundation \\
\hline & MRIF & Manitoba Research and Innovation Fund \\
\hline & $\mathrm{RM}$ & Research Manitoba \\
\hline \multirow[t]{3}{*}{ Ontario } & MOH-LTC & Ministry of Health and Long-Term Care \\
\hline & ORF & Ontario Research Fund \\
\hline & PSI Foundation & Physicians' Services Incorporated Foundation \\
\hline \multirow[t]{3}{*}{ Québec } & AMUQ & Association des Médecins d'Urgence du Québec \\
\hline & Fondation JDC & Fondation Jacques-de Champlain \\
\hline & FRSO & Fonds de Recherche en Santé du Québec \\
\hline New Brunswick & NBHRF & New Brunswick Health Research Foundation \\
\hline Nova Scotia & NSHRF & Nova Scotia Health Research Foundation \\
\hline Prince Edward Island & HSFPEI & Heart and Stroke Foundation of Prince Edward Island \\
\hline Newfoundland & NLCAHR & Newfoundland \& Labrador Centre for Applied Health Res \\
\hline
\end{tabular}

research support structure, and possibly the development of national research training grants were discussed. Finally, the lack of EM representation on peer-review panels and in strategic planning position on national funding agencies was noted.

\section{DISCUSSION AND RECOMMENDATIONS}

There is limited literature or guidance on how to develop effective funding strategies for EM research.
We engaged a panel of experts; collected comprehensive information on funding models from across Canada; listed local, provincial, and national funding opportunities; and summarized U.S. options for EM research support. We believe that the EM community and EM organizations must engage national funding agencies and advocate for greater EM research support to improve patient outcomes. We developed a series of consensus recommendations, received, and incorporated feedback from 


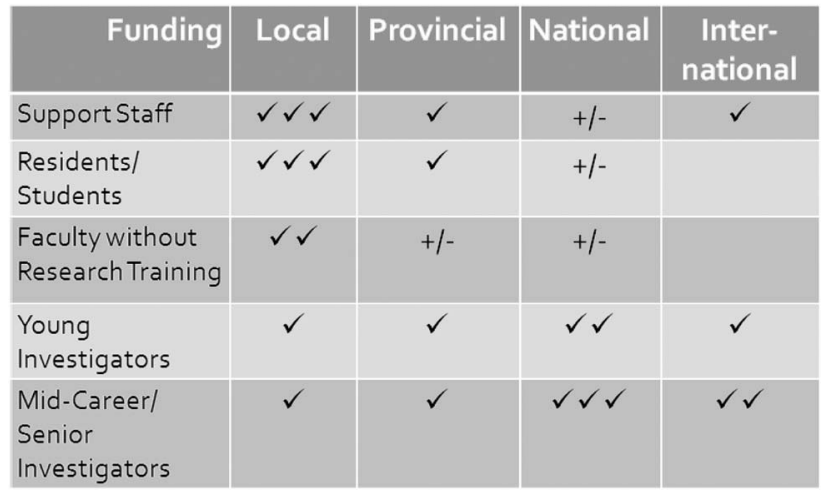

Figure 3. Level of funding most relevant to our target audience.

the academic symposium participants, and organized them according to our predetermined target audience (Boxes 1, 2, and 3).

\section{RECOMMENDATIONS ON HOW TO OBTAIN FUNDING}

Box 1. Recommendations for research contributors and producers, ${ }^{16}$ including learners, faculty members without research training, young investigators, and mid-career and senior investigators.

1. Researchers should obtain research training.

2. Learners should collaborate with and be mentored by trained investigators and/or methodologists in all grant applications.

3. If such mentorship is not available within the EM academic community, efforts should be made to collaborate with investigators from other disciplines, including nonclinician methodologists.

4. Faculty members without research training can start as cosupervisor/collaborator on other learner/faculty member small projects, seek support from an institutional method centre, or collaborate with investigators from other disciplines.

5. Young investigators should be mentored by mid-career/senior investigators, be provided with protected research time in order to increase productivity, and give careful consideration to the timing of their first academic appointment in order to remain eligible for new investigator salary awards.

6. Mid-career/senior investigators should develop research programs leading to large grant opportunities and collaboration with research networks.

7. Mid-career/senior investigators should include funding for trainees, including MSc/PhD students and postdoctoral fellows when applying for all operating grants.
Box 2. Recommendations for local academic leaders.

1. Academic centres should foster a culture of research among their trainees and faculty and reward both participation and excellence.

2. Efforts should be made to train, recruit, and retain investigators interested and dedicated to EM.

3. Local/institutional funding for research activities should be encouraged at all levels of training.

4. Academic centres should strive to implement a mixed-funding model or, at the least, institute a practice plan in order to support research activities.

5. Departments and research groups should consider fundingcontingent positions, where the outside funding used to support a university full-time research position comes from the potential clinician scientist (i.e., clinical income), and this is leveraged by matching dollars or supplements from the faculty or academic department.

Box 3. Recommendations for national organizations.

1. CAEP should maintain and expand its current offering of small grants, and consider larger grants programs such as training grants.

2. CAEP researchers should advocate for EM representation by qualified investigators among national funding agencies such as CIHR.

3. CAEP and EM researchers should advocate for an EM-specific funding stream such as a CIHR EM institute, for example.

\section{LIMITATIONS}

We sought to identify and interview as many academic leaders and researchers as necessary in order to accurately reflect the landscape of local, regional, national, and international research funding strategies. We believe that the funding categories we described are sufficiently broad to encompass most options; it is likely that we identified all successful and innovative funding strategies currently employed in Canada. We acknowledged not having had the intention to produce an exhaustive list of provincial or national funding opportunities. We recognize that new opportunities arise and old ones disappear, so this work must be revisited within the next 5 years. Although we attempted to use a consensus-based approach in order to produce our recommendations on research funding, these are inevitably influenced by the panel 
composition, by the self-selection of those choosing to participate in the academic symposium, and their inherent biases and opinions.

\section{CONCLUSION}

Our review of local or institutional funding strategies identified four funding models: 1) investigator-dependent, 2) practice plan, 3) generous benefactor, and 4) mixed funding, the latter of which appears to represent the most viable model to sustain research activities over time. A summary of our 15 recommendations includes those for 1) research contributors and producers-increased opportunity for mentorship and collaboration with trained investigators or methodologists within or outside EM, and appropriate timing of first academic appointment for young investigators; 2) local academic leaders-foster a culture of research among the faculty and implement a mixedfunding model; and 3) for CAEP-maintain and expand its current offering of small and larger grants, and advocate for increased representation of EM among national funding agencies. We believe that these consensus-based recommendations represent opportunities to increase funding across Canadian emergency departments interested in developing and maintaining a research program, and goals/metrics for future evaluation.

Acknowledgements: We would like to thank CAEP and its Academic Section for their support and assistance with the organization of the academic symposium. We are grateful to the long list of people who donated their time and contributed to this panel (see Figure 1), and to the CAEP 2014 Academic Symposium attendees for their participation and feedback. We would also like to acknowledge the administrative support of Ann Kasaboski, Angela Marcantonio, and Cathy Clement at The Ottawa Hospital Research Institute.

Dr. Brian Rowe is supported as a Tier I Canada Research Chair in evidence-based emergency medicine by the Canadian Institutes for Health Research (CIHR) through the Government of Canada (Ottawa, ON).

Competing interests: None declared.

\section{REFERENCES}

1. Milner RJ, Tisdell EJ, Taylor EW, et al. The essential value of projects in faculty development. Acad Med 2010; 85(9):1484-91.

2. Sherbino J, Van Melle E, Bandiera G, et al. Education scholarship in emergency medicine part 1: innovating and improving teaching and learning. CFEM 2014;16(S1):S1-5.
3. Bandiera G, Leblanc C, Regehr G, et al. Education scholarship in emergency medicine part 2: supporting and developing scholars. CFEM 2014;16(S1):S6-12.

4. Bhanji F, Cheng A, Frank JR, et al. Education scholarship in emergency medicine part 3: a "how-to" guide. CFEM 2014; 16(S1):S13-8.

5. Calder LA, Tierney S, Jiang Y, et al. Patient safety analysis of the ED care of patients with heart failure and COPD exacerbations: a multicenter prospective cohort study. $A m \mathcal{F}$ Emerg Med 2014;32(1):29-35.

6. Emond M, Le Sage N, Lavoie A, Moore L. Refinement of the Quebec decision rule for radiography in shoulder dislocation. CFEM 2009;11(1):36-43.

7. Guttmann A, Schull MJ, Vermeulen MJ, Stukel TA. Association between waiting times and short term mortality and hospital admission after departure from emergency department: population based cohort study from Ontario, Canada. BM7 2011;342:d2983.

8. Innes G, Murray M, Grafstein E. A consensus-based process to define standard national data elements for a Canadian emergency department information system. CFEM 2001; 3(4):277-84.

9. Perry JJ, Stiell IG, Sivilotti MLA, et al. Sensitivity of computed tomography performed within six hours of onset of headache for diagnosis of subarachnoid haemorrhage: prospective cohort study. BMF 2011;343:d4277.

10. Rowe BH, Guo X, Villa-Roel C, et al. The role of triage liaison physicians on mitigating overcrowding in emergency departments: a systematic review. Acad Emerg Med 2011; 18(2):111-20.

11. Schull $M$, Slaughter PM, Redelmeier DA. Urban emergency department overcrowding: defining the problem and eliminating misconceptions. CFEM 2002;4(2):76-83.

12. Stiell IG, Clement CM, Grimshaw J, et al. Implementation of the Canadian C-spine rule: prospective 12 centre cluster randomised trial. BM7 2009;339:b4146.

13. Thiruganasambandamoorthy V, Wells GA, Hess EP, et al. Derivation of a risk scale and quantification of risk factors for serious adverse events in adult emergency department syncope patients. C7EM 2014;16(2):120-30.

14. Carden DL, Dronen SC, Gehrig G, Zalenski RJ. Funding strategies for emergency medicine research. Ann Emerg Med 1998;31(2):179-87.

15. Perry JJ, Snider CE, Artz JD, et al. CAEP 2014 Academic Symposium: "How to make research succeed in your emergency department: How to develop and train career researchers in emergency medicine". CFEM 2015;17(3):334-43.

16. Stiell G, Artz JD, Perry J, Vaillancourt C, Calder L. Executive summary of the CAEP 2014 Academic Symposium: How to make research succeed in your department. CFEM 2015;17(3):328-33.

17. Calder LA, Abu-Laban RB, Artz JD, et al. CAEP 2014 Academic Symposium: "How to make research succeed in your department: Promoting excellence in Canadian emergency medicine resident research". CFEM 2015; forthcoming.

18. Institute of Medicine of the National Academies. Hospitalbased emergency care at the breaking point. The future of emergency care in the United States Health System. Washington, DC: Institute of Medicine of the National 
Academies; 2006. Available at: http://www.iom.edu/ Reports/2006/Hospital-Based-Emergency-Care-At-theBreaking-Point.aspx (accessed 20 January 2015).

19. Institute of Medicine of the National Academies. Emergency care for children: growing pains. The future of emergency care in the United States health system. Washington, DC: Institute of Medicine of the National Academies; 2006. Available at: http://www.iom.edu/Reports/2006/Emergency-Care-forChildren-Growing-Pains.aspx (accessed 20 January 2015).

20. Institute of Medicine of the National Academies. Emergency medical services at the crossroad. The future of emergency care in the United States health system. Washington, DC: Institute of Medicine of the National Academies; 2006. Available at: http://www.iom.edu/Reports/2006/Emergency-MedicalServices-At-the-Crossroads.aspx (accessed 20 January 2015).

\section{APPENDIX 1}

Standardized open-ended questionnaire used for interviews with academic leaders and researchers

Interviewer name:

Date:

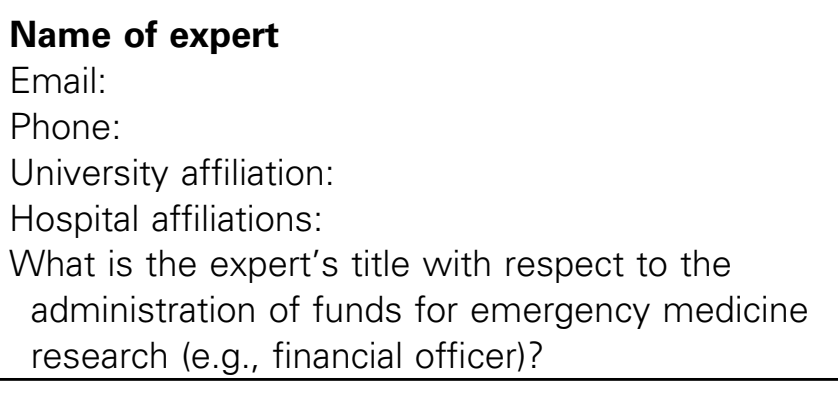

\section{Clinical work}

How is clinical work funded at your hospital?

Do you have a funding agreement? Fee for service? Both?

Do you have a practice plan where some of these clinical funds are pooled to support other activities?
Research work - provincial support

How does the province support emergency medicine research activities?

What is the "formula" or how are the funds distributed?

\section{Research work - hospital support}

How does your hospital distribute these funds to emergency medicine researchers?

What are these funds used for (e.g., leadership positions, administrative staff, education)?

Are there internal (hospital-based) grants for funding research?

If yes, then how are these awarded (e.g., application, points based on scholarly work)?

\section{Research work - university support}

Does your university emergency medicine department receive funds for research?

If yes, then how are these awarded?

What are these funds specifically used for (e.g., research salaries, support services, teaching)?

\section{Research work - research institute}

If there is a research institute(s) affiliated with your hospital or university, can/do emergency medicine researchers receive funding?

Please list the institutes and describe the funding arrangement.

\section{Research work - external grants}

What are the typical external grants used to fund emergency medicine research at your institution (e.g., CIHR, Heart \& Stroke, $\mathrm{NIH}$ ?

Are there any other sources of funding used for supporting research at your institution? 